\title{
SISTEM PAKAR BERBASIS WEB DIAGNOSA JENIS PENYAKIT PADA LAMBUNG MANUSIA
}

\author{
Mukhlis Yuliansyah ${ }^{(1)}$, Bambang Yuwono ${ }^{(2)}$, Dessyanto Boedi $P^{(3)}$ \\ ${ }_{(1,2,3)}$ Teknik Informatika \\ Universitas Pembangunan Nasional "Veteran" Yogyakarta \\ Tambakbayan 2 Babarsari, Yogyakarta \\ Email : bambangy@gmail.com
}

\begin{abstract}
One of the issues touched by the expert system is diagnostic in the field of health, the initial suspicion to diagnose diseases in the human stomach. Gastric disease or disorder can be infected by the disease so that the public needs to be aware. Therefore, the dissemination of information about the disease is needed to find out more types of the disease early. Types of gastric disease is Irritable Bowel Syndrome, Acute Superficial Gastritis, Chronic atrophic gastritis, peptic ulcer, Gastroesophageal Reflux (GERD), Functional Dyspepsia, Gaster Malignant Tumors, Ulcers Gaster. Thus aims to generate web-based expert systems in medicine to diagnose diseases in human gastric symptoms through perceived user. The methodology used for the research of expert system development methods. Methods to build an expert system that Forward Chaining method to search Depth First Search. References from the internet, books and people skilled in the art that dr.Susilaningsih, who worked at the Hospital PKU Muhmammadiyah Yogyakarta. As for the software using PHP as the programming language and MySQL as database.
\end{abstract}

\section{Keyword : Expert System, Disease in The Human Stomach, WEB, Forward Chaining}

Salah satu permasalahan yang disentuh oleh sistem pakar adalah diagnosa dalam bidang kesehatan, yaitu untuk mendiagnosa dugaan awal jenis penyakit pada lambung manusia. Penyakit lambung ini dapat terkena gangguan atau terinfeksi penyakit sehingga perlu diwaspadai oleh masyarakat. Oleh karena itu, penyebaran informasi tentang penyakit ini sangat diperlukan untuk mengetahui lebih dini jenis penyakit yang dideritanya. Jenis Penyakit lambung yaitu Irritable Bowel Syndrome, Gastritis Superfisialis Akut, Gastritis Atrofik Kronik, Ulkus Peptikum, Gastroesophageal Reflux (GERD), Dispepsia Fungsional, Tumor Ganas Gaster,Tukak Gaster. Sehingga bertujuan menghasilkan sistem pakar berbasis web dalam bidang kedokteran untuk mendiagnosa penyakit pada lambung manusia melalui gejala-gejala yang dirasakan pengguna. Metodologi yang dipakai untuk penelitian yaitu metode pengembangan sistem pakar. Metode untuk membangun sistem pakar yaitu Metode Forward Chaining dengan penelusuran Depth First Search. Referensi dari internet, buku dan orang ahli dibidangnya yaitu dr.Susilaningsih, yang bekerja di Rumah Sakit PKU Muhmammadiyah Yogyakarta. Sedangkan untuk software menggunakan PHP sebagai bahasa pemrogramannya,serta MySQL sebagai database.

Kata kunci : Sistem Pakar, Penyakit Lambung, WEB, Forward Chaining

\section{PENDAHULUAN}

Salah satu permasalahan yang disentuh oleh sistem pakar adalah diagnosa dalam bidang kesehatan, yaitu untuk mendiagnosa dugaan awal jenis penyakit pada lambung manusia. Penyakit lambung ini dapat terkena gangguan atau terinfeksi penyakit sehingga perlu diwaspadai oleh masyarakat. Oleh karena itu, penyebaran informasi tentang penyakit ini sangat diperlukan untuk mengetahui lebih dini jenis penyakit yang dideritanya. Jenis Penyakit lambung yaitu Irritable Bowel Syndrome, Gastritis Superfisialis Akut, Gastritis Atrofik Kronik, Ulkus Peptikum, Gastroesophageal Reflux (GERD), Dispepsia Fungsional, Tumor Ganas Gaster, Tukak Gaster. 
Rumusan masalah dari penelitian ini adalah bagaimana membangun sistem pakar berbasis web yang dapat membantu mendiagnosa jenis penyakit pada lambung manusia yang disebabkan oleh berbagai faktor yang ada, serta informasi tentang penyakit lambung.

Batasan masalah dari sistem pakar yang digunakan untuk mendiagnosa jenis penyakit lambung manusia. Ada beberapa batasan dalam penelitian adalah Penyakit yang dibahas dalam sistem ini meliputi Irritable Bowel Syndrome, Gastritis Superfisialis Akut, Gastritis Atrofik Kronik, Ulkus Peptikum, Gastroesophageal Reflux (GERD), Dispepsia Fungsional, Tumor Ganas Gaster, Tukak Gaster. Program ditujukan untuk membantu user, yaitu dalam diagnosa penyakit lambung. Aplikasi ini tidak dapat diikuti oleh penderita selain penyakit.

Tujuan yang diharapkan dari penelitian ini adalah menghasilkan sistem pakar berbasis web dalam bidang kedokteran untuk mendiagnosa penyakit lambung manusia melalui gejalagejala yang dirasakan oleh pengguna.

Manfaat yang diharapkan dari penelitian adalah memberikan kemudahan bagi masyarakat umum untuk dapat mengetahui jenis penyakit lambung yang diderita dengan cepat. Disamping itu dapat memberikan informasi penting tentang macam-macam dari penyakit lambung serta pengobatan secara cepat dan mudah

Metodologi penelitian yang digunakan adalah metode pengembangan sistem pakar, berikut tahapan-tahapan dalam metode pengembangan sistem. (Kusumadewi, 2003).

Penilaian Keadaan, Koleksi Pengetahuan, Perancangan, Tes, Dokumentasi, Pemeliharaan. Namun dalam penelitian ini pelaksanaannya hanya sampai pada tahap dokumentasi tanpa melalui tahap pemeliharaan.

\section{TINJAUAN PUSTAKA}

\subsection{Kecerdasan Buatan}

Kecerdasan buatan (Artificial Intelligence) merupakan bagian dari ilmu pengetahuan computer yang khusus ditujukan dalam perancangan otomatisasi tingkah laku cerdas dalam sistem kecerdasan komputer.

\subsection{Aplikasi Kecerdasan Buatan}

Pengembangan kecerdasan buatan pada awalnya diaplikasikan pada pemecahan masalah, permainan dan matematika, tetapi seiring dengan semakin luasnya pengembangan kecerdasan buatan bersama dengan disiplin ilmu yang lain menghasilkan aplikasi-aplikasi pengembangan yang kemudian dikelompokkan sebagai berikut (Kusumadewi, 2003): Sistem Pakar (Expert system), Pengolahan Bahasa Alami (Natural language Processing), Pengenalan Ucapan (Speech Recognition), Robotika dan Sistem Sensor (Robotics and Sensory Systems), Computer Vision, Intelligent Computer-aided Instruction, Game Playing.

\subsection{Representasi Pengetahuan}

Representasi pengetahuan merupakan kombinasi sistem berdasarkan dua elemen, yaitu struktur data dan penafsiran prosedur untuk digunakan pengetahuan dalam menyimpan struktur data. Hal ini penting untuk merealisasikan kedua elemen tersebut dan dalam sistem representasi pengetahuan adalah suatu hal yang perlu.

\subsection{Sistem Pakar}

Sistem pakar (expert system) adalah program komputer yang dapat merepresentasikan pengetahuan dan memiliki kemampuan untuk memecahkan masalah dan memberikan solusi (Jackson, 1999).

Akhir abad ini,aplikasi tunggal teknik kecerdasan buatan yang terbesar adalah sistem pakar(expert system). Sudah banyak dana dan waktu yang diinvestasikan dalam pengembangan sistem pakar ini, dibanding cabang kecerdasan buatan lainnya.

Sistem pakar adalah program kecerdasan buatan yang menggabungkan basis pengetahuan(knowledge base) dengan sistem inferensi. Inferensi berasal dari bahasa inggris yaitu inference. Inferensi adalah suatu proses memperoleh pengetahuan berdasarkan pengalaman yang terjadi (Andri Kristanto,2004).

\subsection{Mekanisme Inferensi}

Mesin inferensi adalah bagian yang mengandung mekanisme fungsi berpikir dan polapola penalaran sistem yang digunakan oleh seorang pakar. Mekanisme ini akan menganalisa suatu masalah tertentu dan selanjutnya akan mencari jawaban atau kesimpulan terbaik. 
Ada dua teknik yang dapat dikerjakan dalam melakukan inferensi, yaitu :

1. Forward Chaining

Pencocokan fakta atau pernyataan dimulai dari bagian sebelah kiri (IF dulu). Dengan kata lain, penalaran dimulai dari fakta terlebih dahulu untuk menguji kebenaran hipotesis.

2. Backward Chaining

Pencocokan fakta atau pernyataan dimulai dari bagian sebelah kanan (THEN dulu). Dengan kata lain, penalaran dimulai dari hipotesis terlebih dahulu, dan untuk menguji kebenaran hipotesis tersebut harus dicari fakta-fakta yang ada dalam basis pengetahuan .

Kedua metode inferensi tersebut dipenganthi oleh tiga macam penelusuran, yaitu Depthfirst search, Breadth-first search dan Best-first search.

a. Breadth-first search, Pencarian dimulai dari simpul akar terus ke level 1 dari kiri ke kanan dalam 1 level sebelum berpindah ke level berikutnya.

Keuntungan BFS:

1. Breadth first search tidak akan menemui jalan buntu.

2. Jika ada I solusi maka breadth first search akan menemukannya. Jika terdapat lebih dari 1 solusi, maka solusi minimum akan ditemukan.

Kelemahan BFS:

1. Membutuhkan memori yang cukup besar, karena menyimpan semua simpul dalam suatu pohon.

2. Membutuhkan waktu yang cukup lama, karena akan menguji $n$ level untuk mendapatkan solusi pada level yang ke- $(n+1)$.

b. Depth-first search, Pencarian dimulai dari simpul akar ke level yang lebih tinggi. Proses ini dilakukan terus hingga solusinya ditemukan atau jika menemui jalan buntu.

\subsection{Penyakit Lambung}

Lambung terletak oblik dari kiri ke kanan menyilang di abdomen atas tepat dibawah diagfragma. Dalam keadaan kosong lambung menyerupai tabung berbentuk $\mathrm{J}$, dan bila penuh, berbentuk seperti buah pir raksasa.

Jenis Penyakit lambung yaitu Irritable Bowel Syndrome, Gastritis Superfisialis Akut, Gastritis Atrofik Kronik, Ulkus Peptikum, Gastroesophageal Reflux (GERD), Dispepsia Fungsional, Tumor Ganas Gaster, Tukak Gaster (Alwi Setyohadi Sudoyo, 2006)

\subsection{Metode Pengembangan Sistem Pakar}

Metode pengembangan sistem yang digunakan dalam penelitian ini menggunakan metode pengembangan sistem pakar. Terdapat enam tahap atau fase dalam pengembangan sistem pakar. Penjelasan berikut merupakan penjelasan secara garis besar tentang fase-fase pengembangan tersebut.

1. Penilaian keadaan

Tahap ini merupakan tahap penentuan hal-hal penting sebagai dasar dari permasalahan yang akan dianalisis. Tahap ini merupakan tahap untuk mengkaji dan membatasi masalah yang akan diimplementasikan dalam sistem. Setiap masalah yang diidentifikasi harus dicari solusi, fasilitas yang akan dikembangkan, penentuan jenis bahasa pemrograman dan tujuan yang ingin dicapai dari sistem tersebut.

2. Koleksi pengetahuan

Hasil identifikasi masalah dikonseptualisasi dalam bentuk relasi antar data, hubungan antar pengetahuan dan konsep-konsep penting dan ideal yang akan diterapan dalam sistem. Pada tahap ini juga menganalisis data-data penting yang harus didalami bersama dengan pakar dibidang permasalahan tersebut, hal ini dilakukan untuk memperoleh informasi hasil wawancara dan observasi sehingga dapat memberikan jawaban pasti bahwa sasaran permasalahan tepat, benar dan sudah selesai.

3. Perancangan

Pada tahap ketiga ini, data-data yang terdapat pada tahap kedua diimplementasikan secara formal, misalnya memberikan kategori sistem yang akan dibangun, mempertimbangkan beberapa faktor pengambilan keputusan seperti keahlian manusia, tingkat kesulitan yang mungkin terjadi, dokumentasi kerja dansebagainya. Pada tahap ini juga prototype sistem sudah mulai dibangun. Tahap ini diakhiri dengan penyelesaian desain. 
4. Tes

Pada tahap ini sistem telah selesai dibangun dan harus dilakukan evaluasi untuk menguji dan menemukan kesalahannya. Hal ini merupakan hal yang umum dilakukan karena suatu sistem belum tentu sempurna setelah selesai pembuatannya sehingga proses evaluasi diperlukan untuk penyempurnaanya. Dalam evaluasi akan ditemukan bagian-bagian yang harus dikoreksi untuk menyamakan permasalahan dan tujuan akhir pembuatan sistem. Sistem yang telah diinstal di demonstrasikan dan langsung diuji untuk menyelesaikan suatu kasus.

5. Dokumentasi

Dalam tahap ini tes-tes yang telah dilakukan di dokumentasikan agar dapat diperoleh sistem yang baik dan memenuhi standarisasi.

6. Pemeliharaan

Tahap ini menjelaskan tentang hal-hal yang dilakukan setelah sistem diaplikasikan kedunia nyata yaitu bagaimana memelihara, mengembangkan dan melakukan evaluasi sistem secara periodik. Pengembangan sistem diperlukan agar sistem yang akan dibangun tidak menjadi using dan investasi sistem tidak sia-sia. (Kusumadewi,2003):

\section{METODE PENELITIAN}

Metodologi penelitian yang digunakan adalah metode pengembangan sistem pakar, berikut tahapan-tahapan dalam metode pengembangan sistem. (Kusumadewi, 2003).

1. Penilaian Keadaan

2. Koleksi Pengetahuan

3. Perancangan

4. Tes

Dalam sistem ini telah diuji oleh dr. Susilaningsih selaku pakar

4. HASIL DAN PEMBAHASAN

4.1. Tampilan Awal

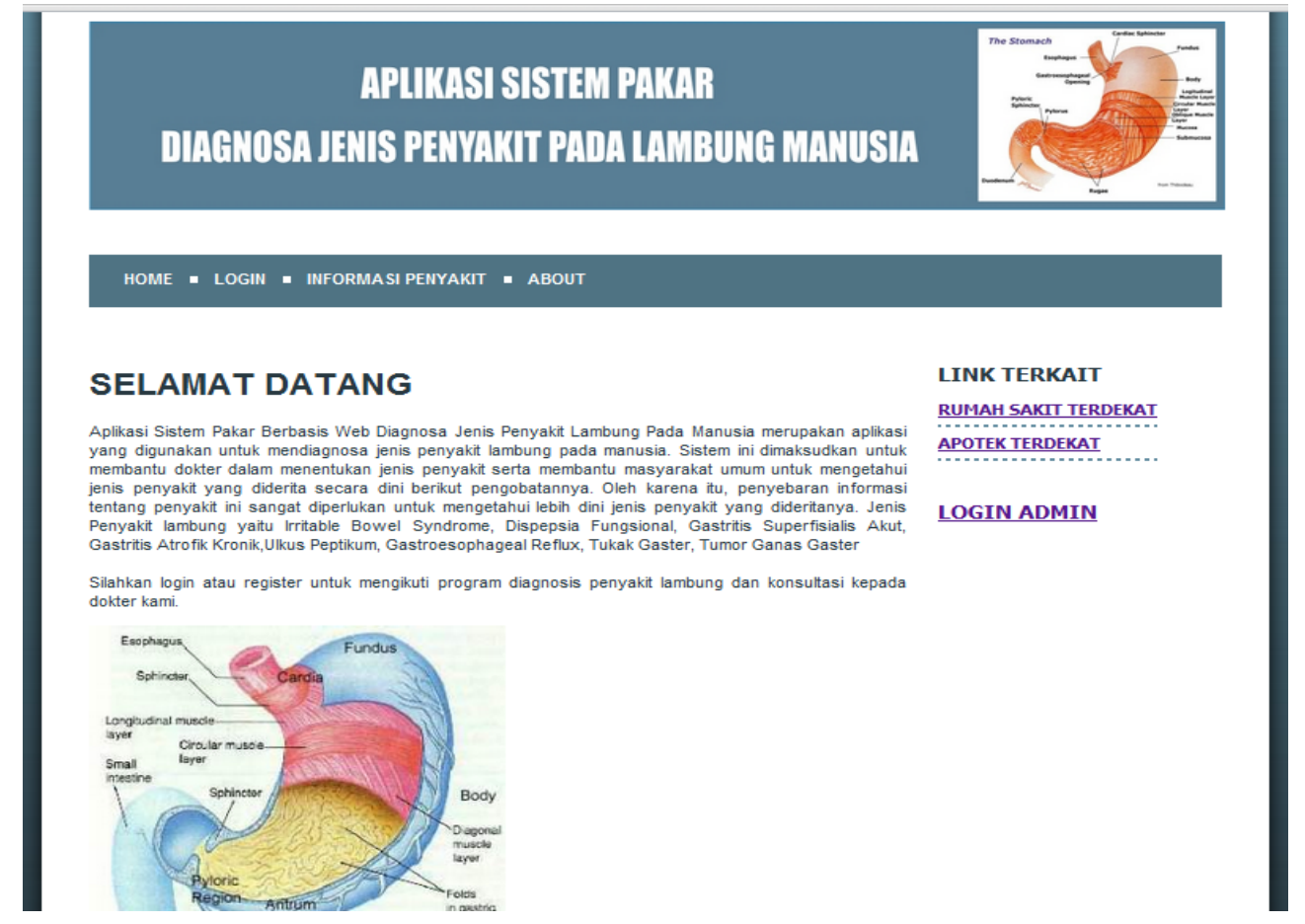

Gambar 4.1. Halaman Depan Program 
Kode program untuk menampilkan menu home adalah sebagai berikut:

$<\mathrm{h} 1>$ SELAMAT DATANG $</ \mathrm{h} 1>$

$<p>$ Aplikasi Sistem Pakar Berbasis Web Diagnosa Jenis Penyakit Lambung Pada Manusia merupakan aplikasi yang digunakan untuk mendiagnosa jenis penyakit lambung pada manusia. Sistem ini dimaksudkan untuk membantu dokter dalam menentukan jenis penyakit serta membantu masyarakat umum untuk mengetahui jenis penyakit yang diderita secara dini berikut pengobatannya. Oleh karena itu, penyebaran informasi tentang penyakit ini sangat diperlukan untuk mengetahui lebih dini jenis penyakit yang dideritanya. Jenis Penyakit lambung yaitu Irritable Bowel Syndrome, Dispepsia Fungsional, Gastritis

Superfisialis Akut, Gastritis Atrofik Kronik,Ulkus Peptikum, Gastroesophageal Reflux, Tukak Gaster, Tumor Ganas Gaster

$<b r><b r>$

Silahkan login atau register untuk mengikuti program diagnosis penyakit lambung dan konsultasi kepada dokter kami.

$</ p>$

$<$ img src="gambar/lambung3.jpg" width="264" height="230">

Modul Program 4.1. Cuplikan Program Untuk Menampilkan Home

\subsection{Tampilan Tes Diagnosa Lambung}

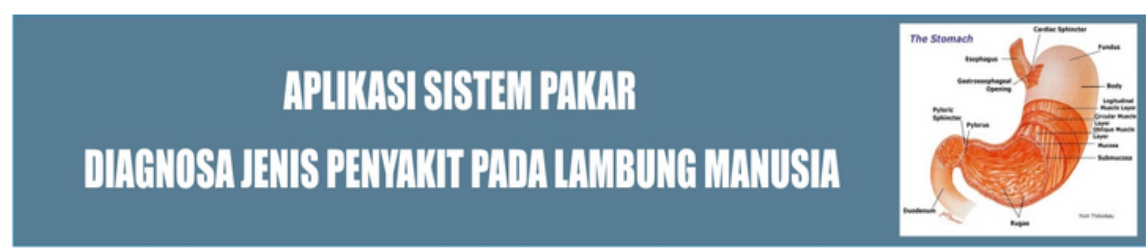

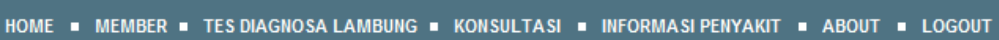

Silahkan Melakukan Tes Diagnosa Penyakit

Apakah anda merasakan gejala dibawah ini?

mengalami anoreksia/ tidak nafsu makan

Y Ya Tidak

Lanjut
LINK TERKAIT

RUMAH SAKIT TERDEKAT

APOTEK TERDEKAT

LOGIN ADMIN

Copyright 2012 | Nukthlis Yuliansyah

Gambar 4.2. Tampilan Menu Tes Diagnosa Lambung

Tampilan menu hasil tes diagnosa dapat dilihat pada gambar sebagai berikut: 


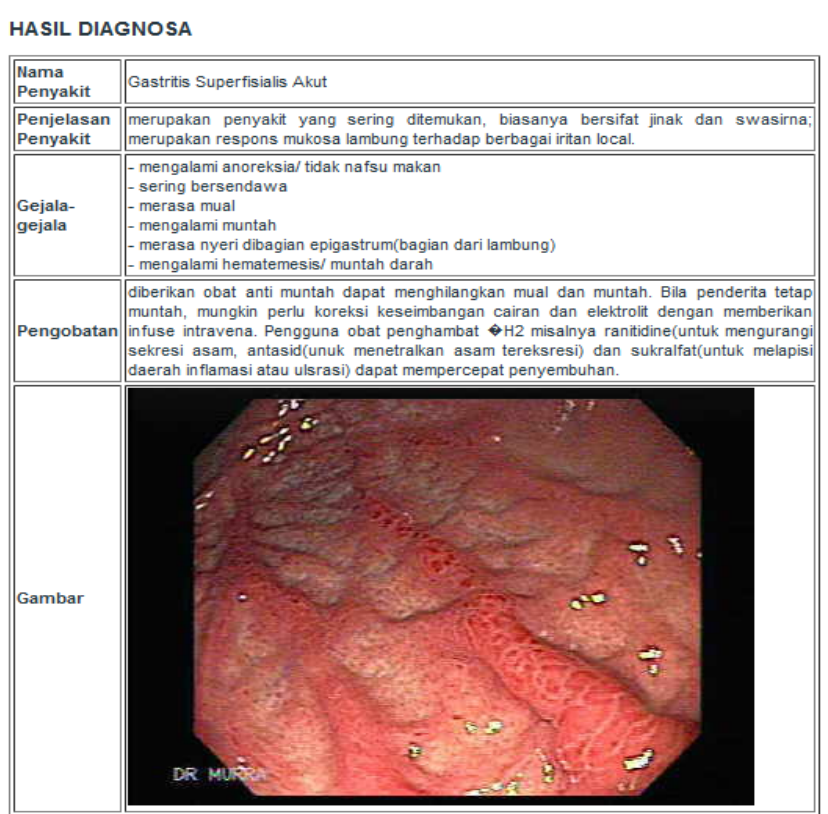

LINK TERKAIT

RUMAH SAKIT TERDEKAT

APOTEK TERDEKAT

LOGIN ADMIN

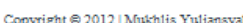

Gambar 4.3. Tampilan Hasil Tes Diagnosa Lambung

\subsection{Tampilan Admin}

\section{LOGIN ADMIN}

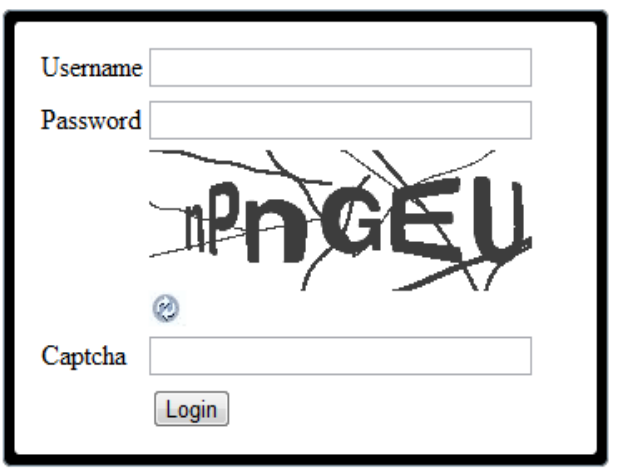

Gambar 4.4. Tampilan Menu Login Admin

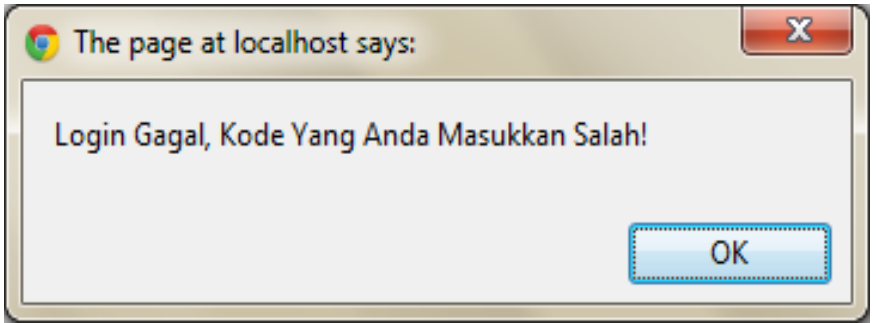

Gambar 4.5. Tampilan Kesalahan Memasukkan Kode 


\subsection{Tampilan Daftar Penyakit}

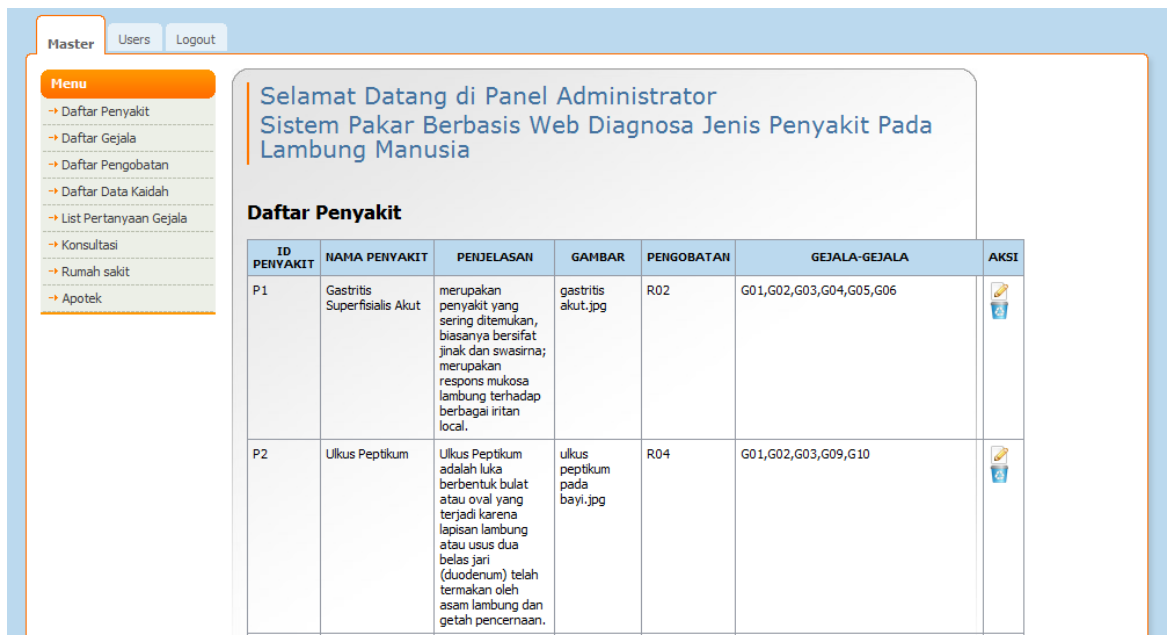

Gambar 4.6. Tampilan Menu Daftar Penyakit

\section{KESIMPULAN}

Setelah dikembangkan sebuah aplikasi sistem pakar berbasis web untuk mendiagnosa jenis penyakit lambung pada manusia, maka dapat ditarik kesimpulan:

1. Telah berhasil dibuat sistem pakar yang mampu berperan sebagai dokter untuk mendiagnosis jenis penyakit lambung pada manusia dan memberikan pengobatannya.

2. Sistem pakar ini hanya dapat melakukan tes diagnosa lambung terhadap penyakit lambung.

3. Dengan adanya pembatasan hak akses yang diterapkan pada sistem, proses untuk mengolah pengetahuan hanya dilakukan oleh seorang admin.

4. Admin berperan aktif dalam penentuan aturan dalam sistem.

5. Sistem bersifat statis.

\section{Saran}

1. Penelitian lebih lanjut dapat menggunakan faktor kepastian

2. Bagi peminat sistem pakar diagnosa penyakit, sistem ini dapat dipakai untuk domain yang lebih luas.

3. Perlu perpaduan pakar beberapa untuk menyempurnakan knowledge sistem pakar ini.

4. Perlu penambahan fitur-fitur lebih lengkap.

5. Perlu sistem cerdas dalam pengambilan keputusan.

6. Sistem ini memiliki kekurangan dalam aturan penentuan penyakit yaitu secara manual, jadi bagi peneliti selanjutnya diharapkan bisa membuat sistem pakar secara efisien dan mudah dioperasikan oleh seorang admin.

\section{DAFTAR PUSTAKA}

Arhami, Muhammad, 2005, Konsep Dasar Sistem Pakar, And, Yogyakarta.

Fatansyah, Ir, 2002, Basis Data, Informatika, Bandung.

Jackson, P, 1999, Introduction to Expert System, Addison Wesley longman Itd, England.

Jogiyanto HM, 1999, Analisis dan Disain Sistem Informasi, Andi, Jakarta.

Kadir, A, 2002, Pengenalan Basis Data, Andi, Yogyakarta.

Kusumadewi, S, 2003, Artifical Intelligence Teknik dan Aplikasinya, Graha Ilmu, Yogyakarta.

Kristanto, Andri, 2004, Kecerdasan Buatan, Graha Ilmu, Yogyakarta.

Setyawan, Sandim, 1993, Artifical Intelligence, Andi Offset, Yogyakarta.

Suparman, 1991, Mengenal Al, Andi, Yogyakarta.

Sutarman, 2003, Membangun Aplikasi Web dengan PHP dan MYSQL Seri Pemrograman Web, Graha Ilmu, Yogyakarta. 
Whitthen, 2004, Metode dan Analisis Sistem, Andi, Yogyakarta.

Ratu, Nurah,2010, PHP adalah, http://www.nurahratu.com/tutorial/web-design/1-latest-

news/203-php-adalah.html,(diakses tanggal 2 Desember 2011).

Sudoyo, Setyohadi, Alwi, 2006, Buku Ajar IImu Penyakit Dalam, Departemen Ilmu Penyakit Dalam FKUI, Jakarta.

Turban, E., Aronson J.E., Liang T.P., 2005, Decision Support System and Intelligent System, Sevenfth Edition, Prentice-Hall International, Inc., New Jersey. 